\title{
INVESTIGATION OF HEART RATE VARIABILITY PARAMETERS AND ANXIETY STATUS OF ACTIVE INDIVIDUALS
}

\author{
Esin Kaplan ${ }^{\mathrm{i}}$ \\ Yozgat Bozok University, \\ Turkey
}

\begin{abstract}
:
The aim of this study is to examine the heart rate variability (HRV) parameters, trait anxiety, and competitive state anxiety levels of active individuals. The research was conducted with a total of 28 men and women aged 18-26 who exercise regularly. Personal information form, trait anxiety inventory, and competitive state anxiety inventory (CSAI2) were applied to the volunteers. Heart Rate Variability measurement was performed using the Heart Math emWave Pro + device. In the analysis of the data, normal distribution criteria were checked using the Shapiro-Wilk test. T-test was used for variables with normal distribution, and Mann Whitney $U$ test was used for variables that did not show normal distribution. Pearson and Spearman correlation analyzes were conducted to examine the relationship between cognitive anxiety, somatic anxiety, and HRV parameters. According to the findings, a statistically significant difference in favor of women was found between the genders in the LF / HF $(\log )(p=.011)$ parameter $(p$ $<0.05)$. According to the correlation analysis, a significant negative correlation was observed between somatic anxiety and the parameters SDNN, RMSSD, LF (Log) (-.457; $.403 ;-.462$ respectively). In conclusion, men and women who exercise regularly have similar anxiety states. It is observed that women have better sympathovagal balance compared to men. The absence of stress parameters that cause impairment in heart rhythm such as anxiety does not cause deterioration in the structure of HRV. In addition, there is a negative correlation between somatic anxiety and some HRV parameters.
\end{abstract}

Keywords: HRV, anxiety, regular exercise

\section{Introduction}

The heart is the most powerful source of energy in the body. It generates rhythmic information patterns in neurological, biochemical, biophysical and energetic ways that continuously communicate with the brain and other body systems in multiple ways. In these ways, the body's organs continuously transmit information to the brain as afferent

${ }^{i}$ Correspondence: email esinkaplan2@gmail.com 
input patterns. Changes in these afferent input patterns cause significant changes in physiological function, perception, cognition, and emotion (McCraty et al., 2009).

Heart rate variability (HRV) is a way of predicting cardiac autonomic nerve activity. HRV varies according to psychophysiological conditions such as stress, relaxation, exercise, as well as age and health. 24-hour HRV measurements are descriptors of the risk of heart disease and mortality (McCraty et al., 2009). As stated before, exercise significantly affects the HRV parameters as it significantly affects the functioning of the heart through the sympathetic nervous system (Kayacan, 2009).

Changes in heart rate are evaluated using time domain and frequency domain methods. The heart rate or the distance between successive normal QRS complexes are determined with time-domain methods (Malik, 1996). Time-domain methods are analyzed statistically and geometrically in two ways. Some parameters of this method are SDNN (standard deviation of NN intervals), RMSSD (mean square of consecutive RR interval differences), HR max-HR min (mean difference between the highest and lowest heart rate during each respiratory cycle) (Shaffer and Ginsberg, 2017). Frequency domain methods are obtained from short and long-term recordings (Kuusela, 2012). Some parameters of this method are LF (Low frequency 0.04-0.15 Hz), HF (High frequency 0.15$0.4 \mathrm{~Hz}$ ), VLF (Very low frequency 0.0033-0.04 Hz), LF / HF (LF HF power ratio) (Shaffer and Ginsberg, 2017).

Some of the HRV parameters are related to sympathetic activity and some to the predominance of parasympathetic activity. RMSSD and HF reflect Vagal function. LF reflects a combination of sympathetic and parasympathetic inputs. The LF / HF ratio reflects the sympathovagal balance. Smaller ratios represent parasympathetic dominance and larger ratios represent sympathetic dominance in the LF / HF parameter (Routledge et al., 2010).

Although anxiety is unpleasant for most people, it is important to our health, safety, and well-being (Spielman et al., 2014). Whatever the situation, some people are more prone to anxiety than others (Jarvis, 2006). The anxiety level and duration of most individuals is related to the magnitude of the potential threat they face (Spielman et al., 2014). Anxiety types is expressed in many ways in the literature. Cognitive anxiety is a mental construct of anxiety and stems from negative expectations. Somatic anxiety refers to the physiological and affective components of the anxiety experience that develops with autonomic arousal. Somatic anxiety is reflected in physical responses such as rapid heart rate, shortness of breath, clammy hands and tight muscles. (Martens et al., 1990). Trait anxiety is the tendency to consider, experience and report negative emotions such as fears and worries in various situations (Gellman, 2012).

Heart rate variability highly reflects stress and emotions (McCraty et al., 2009). It is well known that when people experience stress or anxiety, their autonomic nervous systems are activated. (Spielberger et al., 1971; Lee et al., 2015). In this activation, they experience psychological or physiological arousal such as rapid heart rate, shortness of breath, anxiety, and irritability. Heart rate is more sensitive to stress or anxiety among 
these physical symptoms associated with the activation of the autonomic nervous system (Lee et al., 2015).

Within the framework of this information, the purpose of this research is to determine the heart rate variability parameters, trait anxiety and competitive state anxiety levels of active individuals.

\section{Material and Methods}

The participants of the study consisted of a total of $n=28$ volunteers between the ages of 18-26 years who exercised 60 minutes at least 3 days a week for the last 3 months. Inclusion criteria for the participants; Exercising for at least 3 days a week for 60 minutes for the last 3 months, being between the ages of 18-26 when the study was conducted, having no history of systematic illness, not using any medication regularly due to any illness, and volunteering.

\section{A. Personal Information Form}

A questionnaire prepared by the researchers was applied to collect the participants' level of doing sports and their personal information.

\section{B. Spielberger State- Trait Anxiety Inventory (STAI)}

The trait anxiety inventory part of the State-Trait Anxiety Inventory developed by Speilberger (1976) was used in the study. The adaptation of the scale into Turkish version was conducted by Öner Le Compte (1985). There are 20 statements about trait anxiety in the inventory. Subjects are asked to evaluate how often they experience these expressions on a 4-point Likert-type scale. The internal consistency of the original was found between 0.86-0.92. Structure and criterion validity were also found significant. Internal consistency was found between $0.83-0.87$ in the adaptation study of the inventory to Turkish. In the present study, the Cronbach alpha coefficient is .83.

\section{Competitive State Anxiety Inventory (CSAI-2)}

It is used to measure anxiety before competition in the field of sport psychology. The inventory was developed by Martens et al (1990) and adapted to Turkish version by Koruç (1998). The inventory consists of 4-point Likert-type, three sub-dimensions and 27 items measuring cognitive anxiety, somatic (somatic) anxiety and self-confidence. The factor analysis results of the scale show that the factor loads vary between .68 and .98 for the cognitive anxiety sub-dimension, .69 and .98 for the somatic anxiety sub-dimension, and .75 and .97 for the self-confidence sub-dimension. In the present study, the Cronbach's alpha coefficient was .70 for cognitive anxiety, .79 for somatic anxiety, and .83 for self-confidence. 


\section{Heart Rate Variability Measurement}

The HeartMath emWave Pro+ device was used for Heart Rate Variability (HRV) measurements. The device has data storage and analysis feature through a special computer software. A pulse sensor is placed in the earlobe of the participants for measurement.

Photoplethysmography technology is used to collect data from light reflection variations in capillaries in the earlobe according to cardiac cycle beats. Examination of real-time heart rate variability findings during both the 5-minute and 1-minute deep breath test is based on the ability of hemoglobin to absorb light. The pulse of blood flow in the capillaries is ultimately reflected in the sensor absorption of light from the variable hemoglobin content (Roberto et al.2018).

With the device, data from MHR, SDNN, RMSSD, LF (Log), HF (Log), LF / HF (Log) can be obtained to determine the effectiveness of sympathetic and parasympathetic activity.

\subsection{Procedure}

Participants were asked not to engage in any strenuous activity and consume stimulants (eg caffeine) before their laboratory visits. Measurements were made between 9.00-13.00 in the morning.

Firstly, a questionnaire prepared by the researchers was applied to the paticipants in order to collect their sports level and personal information. Then, they were asked to fill the trait anxiety inventory and the CSAI-2. Participants were asked to recall their emotional state before the last competition they participated in before applying CSAI-2. After the participants rested in a sitting position for 5 minutes, HRV measurements were taken for 5 minutes using the HeartMath emWave Pro + device.

\subsection{Analysis of data}

Statistical analysis of the data was made in the SPSS Program. The Z scores of the data were examined and the extreme values were determined and values other than $-2.50+2.5$ were removed. Later, by performing lost data analysis, assignments were made according to the mean of the series for values with an EM score of $p>0.05$. Since the number of participants was less than 50, the normal distribution criteria were checked using the Shapiro-Wilk test. T test was used for variables with normal distribution, and Mann Whitney $U$ test was used for variables that did not show normal distribution. Pearson and Spearman correlation analyses were conducted to examine the relationship between cognitive anxiety, somatic anxiety and HRV parameters. 


\section{Results and Discussion}

Table 1: HRV Parameters, Competitive State Anxiety Inventory and Trait Anxiety Inventory T-Test results by Gender Variable

\begin{tabular}{|c|c|c|c|c|c|c|}
\hline & Gender & $\mathbf{N}$ & Mean & Sd & $\mathrm{f}$ & $\mathbf{p}$ \\
\hline \multirow[t]{2}{*}{ MHR } & $\mathrm{M}$ & 14 & 77,46 & 10,28 & 120 & 167 \\
\hline & $\mathrm{F}$ & 14 & 83,53 & 12,22 & & \\
\hline \multirow[t]{2}{*}{ LF(Log) } & $\mathrm{M}$ & 14 & 5,84 & 1,01 & ,046 & 832 \\
\hline & $\mathrm{F}$ & 14 & 5,61 & 1,02 & & \\
\hline \multirow[t]{2}{*}{$\mathrm{HF}(\mathrm{Log})$} & M & 14 & 6,34 & 83 & ,344 & ,563 \\
\hline & $\mathrm{F}$ & 14 & 6,47 & 1,00 & & \\
\hline \multirow[t]{2}{*}{$\overline{\mathrm{LF} / \mathrm{HF}(\mathrm{Log})}$} & M & 14 & -.48 & .66 & .679 & $.011^{*}$ \\
\hline & $\mathrm{F}$ & 14 & -1.09 & .51 & & \\
\hline \multirow[t]{2}{*}{ Cognitive Anxiety } & M & 14 & 19,14 & 3,57 & ,231 & 635 \\
\hline & $\mathrm{F}$ & 14 & 18,35 & 3,56 & & \\
\hline \multirow[t]{2}{*}{ Somatic Anxiety } & $\mathrm{M}$ & 14 & 16,77 & 3,25 & ,000 & ,126 \\
\hline & $\mathrm{F}$ & 14 & 18,92 & 3,91 & & \\
\hline \multirow[t]{2}{*}{ Self-confidence } & $\mathrm{M}$ & 14 & 27,71 & 3,91 & 1,665 & 208 \\
\hline & $\mathrm{F}$ & 14 & 28,64 & 4,74 & & \\
\hline \multirow[t]{2}{*}{ Trait Anxiety } & $\mathrm{M}$ & 14 & 38,00 & 7,85 & 118 & 734 \\
\hline & $\mathrm{F}$ & 14 & 36,71 & 7,28 & & \\
\hline
\end{tabular}

${ }^{*} \mathrm{p}<0.05$ F: Female M: Male MHR: Mean Heart Rate; LF(Log): power in low frequency in logarithmic scale; $\mathrm{HF}(\log )$ : power in high frequency in logarithmic scale; $\mathrm{LF} / \mathrm{HF}(\log )$ : ratio between low and high power frequency in logarithmic scale

In Table 1, no significant difference was observed between men and women in MHR, LF $(\log ), \mathrm{HF}(\log )$ parameters according to gender variable. In the LF / HF (log) parameter, a statistically significant difference was found between genders in favor of women ( $\mathrm{p}=$ .011) ( $\mathrm{p}<0.05$ ). Men and women show similarities in cognitive anxiety, somatic anxiety, self-confidence and trait anxiety. In Table 2, KAHD parameters were analyzed according to gender variable with the Mann-Whitney $U$ test.

Table 2: HRV Parameters Mann-Whitney U test results by Gender Variable

\begin{tabular}{|c|c|c|c|c|c|c|}
\hline & Gender & $\mathbf{N}$ & Mean & Sd & $\mathbf{U}$ & p \\
\hline \multirow[t]{2}{*}{ Age } & $\mathrm{M}$ & 14 & 20,57 & 2,06 & 86,000 & ,568 \\
\hline & $\mathrm{F}$ & 14 & 20,50 & 1,22 & & \\
\hline \multirow[t]{2}{*}{ SDNN } & $\mathrm{M}$ & 14 & 86,36 & 28,27 & 80,000 & ,408 \\
\hline & $\mathrm{F}$ & 14 & 78,80 & 33,14 & & \\
\hline \multirow[t]{2}{*}{ RMSSD } & $\mathrm{M}$ & 14 & 79,01 & 33,21 & 77,000 & ,335 \\
\hline & $\mathrm{F}$ & 14 & 73,21 & 38,74 & & \\
\hline
\end{tabular}

SDNN: Standard deviation of NN intervals; RMSSD: Root mean squared standard deviation.

In Table 2, no significant difference was observed between men and women in the HRV parameters (SDNN, RMSSD) according to gender variable ( $p>0.05)$. Table 3 shows the correlation between cognitive anxiety, somatic anxiety and HRV parameters. 


\begin{tabular}{lcccccccc}
\hline \multicolumn{7}{c}{ Table 3: Cognitive, Somatic Anxiety and HRV parameters Correlation results } \\
\hline & CA & SA & MHR & SDNN & RMSSD & LF(Log) & HF(Log) & LF/HF(Log) \\
\hline CA & 1 & $.617^{* *}$ & -.047 & -.043 & .022 & -.142 & .132 & -.275 \\
SA & & 1 & .286 &,$- 457^{*}$ & $-.403^{*}$ & $-.462^{*}$ & -.197 &,- 264 \\
MHR & & & 1 & $-.628^{* *}$ & $-.593^{* *}$ & $-.431^{*}$ & $-.459^{*}$ & -.141 \\
SDNN & & & & 1 & $.937^{* *}$ & $.803^{* *}$ & $.745^{* *}$ & .041 \\
RMSSD & & & & & 1 & $.733^{* *}$ & $.815^{* *}$ & .011 \\
LF(Log) & & & & & & 1 & $.644^{* *}$ & .285 \\
HF(Log) & & & & & & 1 & -.285 \\
LF/HF(Log) & & & & & & & 1 \\
\hline
\end{tabular}

${ }^{*}$ Correlation is significant at the 0.05 level; ${ }^{* *}$ Correlation is significant at the 0.01 level

CA: Cognitive Anxiety; SA: Somatic Anxiety

A significant negative correlation was observed between somatic anxiety and SDNN, RMSSD, LF (Log) parameters. While there was a significant negative correlation between MHR and SDNN, RMSSD, LF (Log), HF (Log) parameters; In positive direction between SDNN and RMSSD, LF (Log), HF (Log) parameters; A positive correlation was observed between LF (Log) and HF (Log) parameters.

Physiological adaptation creates a harmonious and regular heart rhythm pattern known as heart rate variability, which has been proven to facilitate inner ease and balance in life processes. In contrast, irregular, incompatible, asynchronous models reveal an inconsistent system reflecting stress and inefficient energy use in life processes. Negative emotions such as anxiety and worry lead to heart rhythm patterns that appear inconsistent, highly variable, and irregular. This means that there is less synchronization in the mutual action of the parasympathetic and sympathetic branches of the autonomic nervous system. That is, the rhythm of cardiac activity is directly related to the subjective activation of different emotional states. Thus, the heart rhythm pattern reflects changes in emotional states (McCraty et al., 2009).

The present study findings show that both female and male individuals have similar values in cognitive anxiety, somatic anxiety, self-confidence and trait anxiety. Similar anxiety states did not cause differentiation in HRV parameters of active male and female individuals. The literature associates both state and trait anxiety with increased sympathetic cardiac response and decreased vagal activation (Friedman \& Thayer, 1998; Plutchik, H. Kellerman, 1980; Friedman 2007). Chalmers et al. (2014), in their metaanalysis study based on 36 articles, concluded that anxiety disorders are associated with low HRV.

CSAI-2 norms were determined by Martens et al. (1990) for the gender variable as cognitive anxiety (M: $17.68( \pm 4.84)$ F: $18.40( \pm 5.99))$, somatic anxiety (M: $17.68( \pm 4.86)$ F: $16.85( \pm 4.94)$ ) and self-confidence (M: $25.37( \pm 5.15)$ F: 24.67 ( \pm 5.90$)$. In the current study, the CSAI 2 mean values of active men and women seem to meet the norm values (see Table 1).

In the present study, the LF / HF (Log) parameter appears to be statistically lower in women. HF and LF mean values show that women have higher HF and lower LF parameter values. This result reveals that active women show higher vagal activity 
compared to active men. Kohening and Thayer (2016), found that in a meta-analysis study in which healthy individuals examined the HRV according to gender, the power spectral density of HRV in women was characterized by significantly more HF and less total power including less LF parameters. They stated that this situation is also reflected by a lower LF / HF ratio. This meta-analysis study supports the current study findings.

In addition, HRV parameter norms were determined by Nunan et al (2010). According to the average values specified regardless of age is SDNN (50), RMSSD (42). (Shaffer \& Ginsberg, 2017). In the current study, it is seen that the mean HRV parameters of active men and women are above the norm values (see table 2). The fact that the individuals participating in the study were exercising regularly may have affected this situation.

In the literature, it is possible to come across studies stating that regular exercise leads to improvement on HRV parameters. Melanson and Freedson (2001) examined the effect of 12-week endurance exercise applied by sedentary men on HRV in their study. They concluded that a moderate exercise program increased the time and frequency domain measurements of HRV within 12 weeks. Earnest et al. (2008)'s study shows that improvements in HRV through exercise can reduce the risk of mortality. Jurca et al. (2004) concluded that moderate 8 weeks of aerobic exercise increased HRV in sedentary postmenopausal women. Studies show that regular exercise improves HRV parameter values in men and women.

In the present study, a significant negative relationship was observed between somatic anxiety and SDNN, RMSSD, LF (Log) parameters. The presence of somatic anxiety affects the autonomic nervous system, and this leads to imbalances on HRV. Fortes et al. (2017) revealed that cognitive and somatic anxiety has a negative relationship with HRV. They state that athletes with high levels of cognitive and / or somatic anxiety cause higher autonomic nervous system impairment. In the literature, it is possible to find studies examining the relationship between CSAI-2 and HRV parameters. Some studies have found a relationship between competitive state anxiety sub-dimensions and HRV. Some studies state that there is no relationship (Morales et al., 2013; Blásquez et al., 2009; Ayuso-Moreno et al., 2020; Mullen et al., 2012; Mateo et al., 2012; Paula et al., 2016).

\section{Recommendations}

The present study was evaluated by considering the anxiety situations perceived by the individuals. In future studies, evaluating HRV by creating a mental or physical stress situation may contribute to the literature.

\section{Conclusion}

As a conclusion, men and women who exercise regularly have similar anxiety states. On the other hand, it is seen that women have better sympathovagal balance on HRV parameters than men. The absence of stress parameters that cause impairment in heart 
rhythm such as anxiety does not cause impairment on the HRV structure. In addition, there is a negative relationship between somatic anxiety and some HRV parameters.

\section{Conflict of Interest Statement}

The author declares no conflict of interest.

\section{About the Authors}

Esin Kaplan was born in Antalya in 1985. Between 2003-2009, she graduated from Akdeniz University, Faculty of Sport Sciences, Department of physical education and sports. Between 2012-2014, she completed her master's degree in Akdeniz University Institute of Health Sciences, Department of Physical Education and Sports Sciences Program. Between 2016-2021, she completed her PhD in Akdeniz University Institute of Health Sciences, Department of Sports Sciences Program.

\section{References}

Ayuso-Moreno R M, Fuentes-García J P, Collado-Mateo D \& Villafaina S, 2020. Heart Rate Variability and Pre-Competitive Anxiety According to The Demanding Level of The Match in Female Soccer Athletes. Physiology \& Behavior, 112926. https://doi.org/10.1016/j.physbeh.2020.112926

Blásquez J CC, Font G R, Ortís L C, 2009. Heart-rate variability and precompetitive anxiety in swimmers. Psicothema 21(4), 531-536.

Chalmers J A, Quintana D S, Abbott M J, Kemp A H, 2014. Anxiety Disorders are Associated with Reduced Heart Rate Variability: A Meta-Analysis. Frontiers in Psychiatry, 5, 80.

Earnest C P, Lavie C J, Blair S N, Church T S, 2008. Heart Rate Variability Characteristics in Sedentary Postmenopausal Women Following Six Months of Exercise Training: The DREW Study. Plos One, 3(6), e2288.

Friedman B H, 2007. An Autonomic Flexibility-Neurovisceral İntegration Model of Anxiety and Cardiac Vagal Tone. Biological Psychology, 74(2), 185-199.

Friedman B H, Thayer J F, 1998. Autonomic balance revisited: panic anxiety and heart rate variability. Journal of psychosomatic research, 44(1), 133-151.

Fortes L S, da Costa B D, Paes P P, do Nascimento Júnior J R, Fiorese L, Ferreira M E, 2017. Influence of Competitive-Anxiety on Heart Rate Variability İn Swimmers. Journal of Sports Science \& Medicine, 16(4), 498.

Gellman M D, Turner J R, 2013. Encyclopedia of behavioral medicine, Springer New York, USA

Jarvis M, 2006. Sport psychology: A student's handbook. Routledge.119-120

Jurca R, Church T S, Morss G M, Jordan A N, Earnest C P, 2004. Eight Weeks of ModerateIntensity Exercise Training İncreases Heart Rate Variability in Sedentary Postmenopausal Women. American Heart Journal, 147(5), e8-e15. 
Koenig J, Thayer J F, 2016. Sex Differences in Healthy Human Heart Rate Variability: A Meta-Analysis. Neuroscience \& Biobehavioral Reviews, 64, 288-310.

Koruc Z, 1998. CSAI-2'nin Turkce uyarlamasi (The adaptation of CSAI-2 in Turkish). V. Congress on Sport Sciences. Ankara: Hacettepe Üniversitesi, 93

Kuusela T, 2012. Methodological aspects of heart rate variability analysis. In: Kamath M V, Watanabe M, Upton A, Eds. Heart rate variability (HRV) signal analysis: clinical applications. CRC Press, p:11-21

Lackey E D, 2014. Self-Regulation and heart rate variability coherence: promoting psychological resilience in healthcare leaders. PhD Thesis, University of Benedictine

Lee J, Kim J K, Wachholtz A, 2015. The Benefit of Heart Rate Variability Biofeedback and Relaxation Training in Reducing Trait Anxiety. Han'guk Simni Hakhoe Chi. Kon'gang The Korean Journal of Health Psychology, 20(2), 391.

Malik M, 1996. Heart Rate Variability: Standards of Measurement, Physiological Interpretation, and Clinical Use: Task Force of The European Society Of Cardiology and The North American Society For Pacing and Electrophysiology. Annals of Noninvasive Electrocardiology, 1(2), 151-181.

Martens R, Vealey R S, Burton D, 1990. Competitive State Anxiety in Sport. Champaign IL: Human Kinetics Publishers, 117-190.

Mateo M, Blasco-Lafarga C, Martínez-Navarro I, Guzmán J F, Zabala M, 2012. Heart Rate Variability and Pre-Competitive Anxiety in BMX Discipline. European Journal of Applied Physiology, 112(1), 113-123.

McCraty R, Atkinson M, Tomasino D, Bradley R T, 2009. The Coherent Heart Heart-Brain Interactions, Psychophysiological Coherence, and the Emergence of System-Wide Order. Integral Review: A Transdisciplinary \& Transcultural Journal for New Thought, Research, E Praxis, 5(2).

Melanson E L, Freedson P S, 2001. The Effect of Endurance Training on Resting Heart Rate Variability in Sedentary Adult Males. European Journal of Applied Physiology, 85(5), 442-449.

Morales J, Garcia V, García-Massó X, Salvá P, Escobar R, 2013. The Use of Heart Rate Variability in Assessing Precompetitive Stress in High-Standard Judo Athletes. International Journal of Sports Medicine, 34(02), 144-151.

Mullen R, Faull A, Jones E S, Kingston K, 2012. Attentional Focus and Performance Anxiety: Effects on Simulated Race-Driving Performance and Heart Rate Variability. Frontiers in Psychology 3(1), 1-10.

Öner N, Le Compte A, 1985. Durumluluk-Surekli Kaygi Envanteri El Kitabi, İstanbul. Boğaziçi Üniversitesi Yayınları.

Paula Jr E P, Paza D L S, Pierozan G C, Stefanello J M F, 2016. Heart Rate Variability and Emotional States in Basketball Players. Journal of Exercise Physiology Online, 19(6).

Plutchik R, Kellerman H, 1980. Emotion, theory, research, and experience. Academic press. 
Roberto C, Giuseppe D İ, Attilio C, 2018. Heart Rate Variability: An Overview and a Few İmmediate/Short-Term Assessments. Heart and Mind, 2(4), 111.

Routledge F S, Campbell T S, McFetridge-Durdle J A, Bacon S L, 2010. Improvements in Heart Rate Variability with Exercise Therapy. Canadian Journal of Cardiology, 26(6), 303-312.

Sammito S, Thielmann B, Seibt R, Klussmann A, Weippert M, Böckelmann I, 2015. Guideline for the application of heart rate and heart rate variability in occupational medicine and occupational science. ASU Int.

Shaffer F, Ginsberg J P, 2017. An Overview of Heart Rate variability Metrics and Norms. doi: 10.3389/fpubh.2017.00258

Spielberger C D, Gonzalez-Reigosa F, Martinez-Urrutia A, Natalicio L, Natalicio D S, 1971. Development of the Spanish Edition of The State-Trait Anxiety İnventory. Interamerican Journal of Psychology, 5(3-4), 145-158.

Spielman R M, Dumper K, Jenkins W, Lovett M, Perlmutter M, 2014. Psychology. Rice University, Textbook, 550-551 
Esin Kaplan

INVESTIGATION OF HEART RATE VARIABILITY

PARAMETERS AND ANXIETY STATUS OF ACTIVE INDIVIDUALS

Creative Commons licensing terms

Authors will retain the copyright of their published articles agreeing that a Creative Commons Attribution 4.0 International License (CC BY 4.0) terms will be applied to their work. Under the terms of this license, no permission is required from the author(s) or publisher for members of the community to copy, distribute, transmit or adapt the article content, providing a proper, prominent and unambiguous attribution to the authors in a manner that makes clear that the materials are being reused under permission of a Creative Commons License. Views, opinions and conclusions expressed in this research article are views, opinions and conclusions of the author(s). Open Access Publishing Group and European Journal of Physical Education and Sport Science shall not be responsible or answerable for any loss, damage or liability caused in relation to/arising out of conflict of interests, copyright violations and inappropriate or inaccurate use of any kind content related or integrated on the research work. All the published works are meeting the Open Access Publishing requirements and can be freely accessed, shared, modified, distributed and used in educational, commercial and non-commercial purposes under a Creative Commons attribution 4.0 International License (CC BY 4.0). 